\title{
Failure propagation in multi-cell lithium ion batteries
}

\author{
Joshua Lamb*, Christopher J. Orendorff, Leigh Anna Steele and Scott Spangler
}

Advanced Power Sources R\&D, Sandia National Laboratories

*Corresponding author: (O) 505-284-9709; (F) 505-844-6972; jlamb@sandia.gov

\section{Abstract}

Traditionally, safety and impact of failure concerns of lithium ion batteries have dealt with the field failure of single cells. However, large and complex battery systems require the consideration of how a single cell failure will impact the system as a whole. Initial failure that leads to the thermal runaway of other cells within the system creates a much more serious condition than the failure of a single cell. This work examines the behavior of small modules of cylindrical and stacked pouch cells after thermal runaway is induced in a single cell. Cylindrical cells are observed to be less prone to propagate owing to the limited contact between neighboring cells. The electrical connectivity is found to be impactful as the 10S1P cylindrical cell module did not show failure propagation through the module, while the 1 S10P module had an energetic thermal runaway consuming the module minutes after the initiation failure trigger. Modules built using pouch cells conversely showed the impact of strong heat transfer between cells. In this case, a large surface area of the cells was in direct contact with its neighbors, allowing failure to propagate through the entire battery within 60-80 seconds for all configurations (parallel or series) tested.

Keywords: lithium ion safety; thermal runaway; failure propagation; battery abuse; multi cell

\section{Introduction}

Studies on the safety of lithium ion batteries (LIB) have long focused on the impact and aftermath of the field failure of a single cell. This has been driven by the fact that LIB have traditionally been used for small devices where 1) failure of a single cell would have little impact beyond the device and its user, and 2) the battery is unlikely to see a truly abusive condition under normal use. As LIB are considered for larger systems, including vehicle electrification and electric grid applications such as 
energy storage and smart grid applications, the impact of the failure of single cells and small groups of cells must be reexamined. Recent incidents have seen thermal events that have eventually consumed entire battery systems, stemming from myriad initial causes including mechanical intrusion [1], overheating [2] and overvoltage/overcharging. [3] Not only are the causes of failure becoming more diverse, but the impact of these failures is increasing as well. However, few systemic studies have been performed to determine how a localized thermal runaway event may impact a battery system as a whole, regardless of the initial mode of failure.

The thermal runaway behavior of single lithium ion cells is well studied. [4-16] Typical responses include venting of battery gasses, ejection of cell contents, extreme temperatures and in some cases self-ignition of the cell or ejected battery materials. What is less well known is how these behaviors may impact a larger, more complex system. The failure of a single cell taken on its own may have little impact on the safety or performance of an electric vehicle system; however, the thermal and electrical impact on other cells in the system may be sufficient to cause a cascading runaway effect. In this scenario, the energetic thermal runaway of a single cell provides enough heat to neighboring cells within the battery to initiate thermal runaway in the neighbors. These cells then provide enough heat to chain the failure to their neighbors, continuing until the entire battery pack has been consumed. This worst-case scenario would result in a catastrophic release of energy within the confines of an electric vehicle causing significant damage and presenting a potentially dangerous situation for the operator. This possibility of propagation through a pack was modeled by Spotnitz et al. [16]. This work proposed that the likelihood of full battery pack failure was influenced by several factors, including the abuse response of the individual cells and the overall insulation of the pack. Particularly important, though, is the thermal contact to other cells, and they predicted that cells directly neighboring multiple other cells were more likely to cause a propagation through a battery pack. 
The electrical configuration of cells may impact how failure propagates as well. Offer et al. [17] showed that even under normal conditions varying resistances of connections between cells within a battery module may impact the local temperature of a cell. It is common practice as well to use blocking and discharge diodes within large parallel battery packs to prevent self-discharge of the battery through a shorted cell. [18] However, the thermal separation between cells is often limited. Prismatic and pouch cells are often packed together either face to face or separated by thin plates used for active cooling. [19] Even if they are thermally separated the electrical connections themselves have been shown to provide a path for heat transfer between cells. [13]

Recent work exploring behavior of battery systems has largely been focused on long-term performance issues; $[17,19-24]$ however some information on failure propagation may be inferred. Much of the current handling of cell faults in battery packs involves the diagnosis and electrical handling of faulty cells within a system. Various methods exist for the detection of faulty cells, [21] and Kim et al. [20] described a method for electrically isolating faulty cells from the battery pack. The science of fault detection is still in its infancy, and the most reliable indicators of battery health are still voltage and temperature monitoring of cells. Unfortunately, when considering battery safety, changes in cell voltage or temperature are only symptoms of a different issue and are not indicators of a root cause. These indicators often lag a root cause, and by the time a significant temperature increase or voltage change is observed the cell is undergoing a thermal runaway event that is too late to arrest.

The work presented here examines the failure propagation behavior of small battery modules constructed with cylindrical 18650 cells and stacked pouch cells. The impact of electrical configuration (series vs. parallel) is evaluated as well. This will examine both the propensity of different constructions to have a propagating thermal runaway and the behavior of the propagation once it occurs. This provides a method for better understanding the potential impacts of a single cell failure on a larger battery system, as well as provides new data to inform the design of batteries. 


\section{Experimental Methods}

Thermal runaway was initiated using a mechanical nail penetration. Previous work found that nail penetration parallel to the axis of cylindrical cells could be reliably used to create a hard internal short and thermal runaway for a given cell type. [25] Similarly, the same work observed that thermal runaway could be induced using nail penetration into the side of a stacked pouch cell. This provides a method for inducing thermal runaway within a single cell of a multi-cell battery module without adding any additional thermal or electrical energy to the cell.

Modules for failure propagation were constructed using commercially available cells. 18650 modules were constructed using Panasonic CGR18650CG cells with a nominal capacity of $2200 \mathrm{mAh}$. The 18650 test articles were constructed as 10 cell modules fully series (10S1P) and fully parallel (1S10P) configurations, with electrical connections made using $0.005^{\prime \prime} \times 0.200^{\prime \prime}$ nickel ribbon. The cells were held together in a close module configuration. Thermocouples were attached to cells facing towards the center of the module. A schematic of the physical layout of the 18650 modules with thermocouple placements is shown in Figure 1.

The propagation tests on the 18650 test modules were performed by creating a hard shorting failure within the central cell (Cell 6) using mechanical nail penetration. The nail was inserted through the bottom of the cell can using a hydraulic press at a rate of $2 \mathrm{~cm} / \mathrm{second}$ to a depth of $20 \mathrm{~mm}$. The module was monitored for the propagation of the energetic failure through the remaining cells. Battery temperatures, module voltage and individual cell voltages of the 10S1P module were collected and evaluated.

Stacked pouch cell modules were constructed as 5 cell batteries using AA Portable Power Corp. model 7035130-10C 3,000 mAh cells. The modules were constructed in fully series (5S1P) and fully parallel (1S5P) configurations, with electrical connections made using $0.005 \times 0.200$ " nickel ribbon. The cells were fixed together in a close packed, stacked orientation with the largest part of the cell face 
directly in contact with its neighbors. Thermocouples were placed between each cell as well as on the outer faces of the module, and the module held together using $0.5^{\prime \prime}$ phenolic board as constraints. A schematic of cell layout and thermocouple placement can be seen in Figure 2.

The propagation test on the stacked pouch modules was performed by creating a hard short circuit condition within one cell using a sharp nail penetration. The nail was inserted into the target cell at $2 \mathrm{~cm} /$ second up to $20 \mathrm{~mm}$. The central cell (Cell 3) and an edge cell (Cell 1) were failed in separate tests. The propagation of cell failure was monitored using temperature measurements, as well as cell voltage measurement of series modules.

\section{Results and discussion}

Table 1 details the configurations of the modules tested. The response of these cells to mechanical nail penetration and blunt rod indentation have been determined previously and are reported in reference [25]. It was observed in the previous work that nail penetration could be used to produce a repeatable thermal runaway event in the cells tested. Due to the difficulty and costs of performing destructive testing, the total number of tests performed is somewhat limited. While repeat tests of the data observed here were conducted, a deep statistical analysis featuring a large number of tests may yield different results.

Table 1. Cell and battery specifications for test articles used for propagation testing

\begin{tabular}{|c|l|l|l|}
\hline \multicolumn{1}{|c|}{ Battery } & \multicolumn{1}{c|}{ Chemistry } & \multicolumn{1}{c|}{ Geometry } & \multicolumn{1}{c|}{ Configuration } \\
\hline $2200 \mathrm{mAh} 18650$ & $\mathrm{LiCoO}_{2} /$ Graphite & cylindrical & $10 \mathrm{~S} 1 \mathrm{P}, 1 \mathrm{~S} 10 \mathrm{P}$ \\
\hline $3000 \mathrm{mAh}$ pouch & $\mathrm{LiCoO}_{2} /$ Graphite & pouch & $5 \mathrm{~S} 1 \mathrm{P}, 1 \mathrm{~S} 5 \mathrm{P}$ \\
\hline
\end{tabular}

\subsection{Propagation Testing 10S1P and 1S10P Cylindrical Cell Batteries}

\subsubsection{S1P}

Figure 3 shows the temperature response of the 10S1P propagation test initiated at Cell 6. Cell 6 goes into thermal runaway and self-ignites with a peak temperature of $360^{\circ} \mathrm{C}$ (initiated at 265 seconds in Figure 3). The sustained fire causes an initial temperature rise in all of the thermocouples on the cells 
with the exception of Cell 10 which has a thermocouple that is sufficiently well separated from the fire. Approximately 15 seconds after the initiation, an electrolyte fire ignites from electrolyte that had leaked from Cell 6 which caused a more sustained temperature increase in the Cell 2, 3 and 9 thermocouples but no evidence of thermal runaway in those cells. Several cells audibly vent during this test, but there is no evidence of thermal runaway in any cell other than Cell 6.

The module and cell voltage responses of the 10S1P battery to the propagation test are shown in Figure 4. After the penetration of Cell 6, the voltages of Cells 1, 2, 3, 5 and 7 also drop but recover during the test with the exception of Cell 1. The Cell 8 voltage is also very noisy after the initial Cell 6 failure, but settles out over time. The noise in voltage channels could be attributed to heating from the initial fire that ignited after the Cell 6 failure. It is interesting to note that Cell 1 voltage is most affected by the Cell 6 failure and not an adjacent cell ( 5 or 7 ), but there is no evidence of thermal runaway of Cell 1. Figure 5 shows a picture of the battery completely intact post-test. Thermal runaway failure initiated at Cell 6 clearly impacts the measured voltage of Cell 1, but no thermal runaway propagation to other cells is observed.

Ultimately, while the initial runaway of Cell 6 generates a significant amount of heat, the thermal conductivity between neighboring cells is relatively low. Firstly, even in a closely packed geometry such as that used here, there is a significant air gap between the cylindrical cells. Further, any shorting that occurs within the battery in a fully series configuration will not impact the general operability of the other cells; the battery module could conceivably still be operated albeit at a lower voltage to account for the missing cell.

\subsubsection{S10P}

Figure 6 shows the cell skin temperature, and Figure 7 shows the battery voltage during the 1S10P propagation test. Failure is initiated at Cell 6 which, results in self-ignition and relatively small sustained electrolyte fire. This sustained electrolyte fire continues as the other cells vent and leak 
electrolyte over the course of several minutes. While there are elevated temperatures recorded by the thermocouples on the skin of each cell there is no evidence of thermal runaway at times $<400 \mathrm{~s}$. Module voltage is lost at $\sim 200$ seconds (Figure 10). At approximately 420 seconds, Cells 2 and 9 go into an energetic thermal runaway and that failure quickly propagates through the rest of the battery (approximately $290 \mathrm{~s}$ after the initiation at Cell 6). Skin temperatures of the cells measured during the runaway are between $600-900{ }^{\circ} \mathrm{C}$, with some thermocouples reading saturation at $1270{ }^{\circ} \mathrm{C}$ (likely destroyed in the fire). Figure 8 shows the significant damage to the battery post-test. Unlike the 10S1P configuration, the failure of Cell 6 propagates completely through the 1S10P battery.

This shows a significantly different result from the 10S1P module, with a propagating failure that is able to eventually consume the entire module. While the geometry of the module is unchanged there are some potential impacts from the change in electrical connectivity. Firstly, the electrical connections themselves provide a conductive path to other cells in the module; while in the series configuration the electrical conductors only provide a path to the cells directly before and after Cell 6 in the string. Therefore, the parallel configuration provides a path for heat transfer from Cell 6 to all other cells in the module. Further, in a parallel configuration creating a short on an internal cell effectively creates a short circuit load at the point of failure. This creates additional heat generation from 1) the excessive discharging of cells within the module, 2) the flow of current through the bus material connecting the module together and 3) resistive heating at the point of failure itself. Wu et al. [23] and Offer et al. [17] showed that cells nearest the load point can discharge at a greater rate due reduced resistance between the cells and the load point, leading to increased heating of cells near the load point. The elevated temperatures created by the initial runaway also brought the module to a point where the runaway of any additional cell was likely to provide enough heat to send the remainder of the module into thermal runaway. 


\subsection{Propagation Testing 5S1P and 1S5P Pouch Cell Batteries}

\subsubsection{S1P}

The propagation test of the 5S1P pouch cell battery is initiated by a nail penetration at the edge of Cell 3 (center cell). Thermocouples are placed between cells (labeled C1-2 for the thermocouple between Cells 1 and 2) and on the outside of the ends of the battery (Cells 1 and 5). Figure 9 shows the cell skin temperature and battery voltage as a function of time during the propagation test. Figure 10 shows the battery and individual cell voltages during the 5S1P propagation test. Nail penetration of Cell 3 results in a short circuit and thermal runaway with a sharp temperature rise of the C2-3 thermocouple and a loss in the Cell 3 voltage. The failure propagates outward from Cell 3 to Cell 2, Cells 4 and 1, and finally Cell 5 with a full thermal runaway of the battery over the course of approximately 60 seconds. Figure 11 shows a picture of the 5S1P battery post-propagation test.

Results from the pouch cell and cylindrical cell batteries in the series configurations are notably different. The failure quickly propagates completely through the pouch cell battery, but not in the cylindrical cell battery. This suggests that in the series pouch cell battery, propagation of failure is dominated by heat transfer from cell-to-cell because of the good thermal contact over the largest surface area of the cells.

With heat transfer through the surface area of the cells dominating the propagation process, initiation at the center of the battery is likely to be the most severe test condition. Failure propagation through the 5S1P pouch cell battery is also evaluated with initiation at the end of the battery (at Cell 1 ) which is expected to be a less severe condition. Figure 12 shows the cell skin temperature and battery voltage of the 5S1P propagation test initiated at Cell 1. Figure 13 shows the battery and individual cell voltages for this test. Nail penetration of Cell 1 results in a short circuit, loss of cell voltage and thermal runaway of Cell 1 where the skin temperature is measured to be $>200{ }^{\circ} \mathrm{C}$ on the outside of the cell (C-1) and $>600{ }^{\circ} \mathrm{C}$ at the inside face of the cell (C1-2). Just as observed for the Cell 3 initiation experiment, 
failure propagates through the entire 5 -cell battery when failure is initiated at Cell 1 , resulting in full thermal runaway of the battery. The total propagation time is approximately 80 seconds, which is longer than observed for the propagation event when initiated at Cell 3. Since propagation takes place serially from one end of the battery to the other, it is rational to expect the duration of the propagation event to be longer than if initiation is triggered in the center of the battery. Even for initiation at the end of the battery, the heat transfer through the contact surface area between cells is still sufficiently high to cause the failure to propagate completely through the 5S1P battery. Figure 14 shows the remains of the battery after the 5S1P test initiated at Cell 1.

The 5S1P module with initial failure at Cell 1 provides an opportunity to examine how temperature propagates through the module, as the propagation of failure occurs entirely in one direction and is not impacted by cells discharging through the created short circuit. The cell average temperatures are determined as the simple average of the temperatures measured at each cell face and are profiled in Figure 15. This shows the rough temperature distribution through the module first as a result of the initial failure, then as the failure propagates through the cell. Cell 1 can be seen increasing to $285{ }^{\circ} \mathrm{C}$ in the first 10 seconds, elevating Cell 2 with it. At 20 seconds Cell 1 reaches its peak temperature of $403{ }^{\circ} \mathrm{C}$, while Cell 2 reaches a high enough temperature to likely begin self-heating. At this point as well temperature rise is observed in Cell 3. By 30 seconds, full runaway is apparent in Cell 2 as it has exceeded the temperature of the initial cell runaway, peaking by 40 seconds after the initial failure. Cell 3 has heated significantly by this point, and by 50 seconds in shows signs of runaway itself, also beginning to elevate the temperature of cell 4 significantly. After 60 seconds Cell 3 has reached its peak temperature of $630{ }^{\circ} \mathrm{C}$ and Cell 4 is over $300^{\circ} \mathrm{C}$ as well. Cell 4 continues to heat reaching a peak of $\sim 640{ }^{\circ} \mathrm{C}$ after 80 seconds, at which point Cell 5 has reached $340^{\circ} \mathrm{C}$. By 100 seconds Cell 5 begins to cool, signaling the end of thermal runaway. These profiles make apparent that when thermal conductivity between cells is sufficiently strong a propagating thermal runaway can travel through a module through 
the generated heat alone. Another observation of note is that the maximum temperature reached by each cell increased as the runway progressed through the battery (except for Cell 5, which was bounded by the inert constraint). This demonstrates how involving more and more cells in a propagating failure will increase not only the total energy involved in the event, but can also increase the acute severity as the cells reach temperatures as part of the propagating failure that they would not under an individual runaway event.

\subsubsection{S5P}

Pouch cell battery failure propagation is also evaluated for batteries in the 1S5P configuration, where failure is initiated by a nail penetration at the center of the battery (Cell 3). Figure 16 shows the cell skin temperatures and battery voltage for the 1S5P propagation test. As observed in the 5S1P experiments, failure propagates completely through the 1S5P batteries. Again, the thermal contact over the large surface area between the cells dominates the propagation mechanism as opposed to electrical connectivity. The data from the 10S1P and 1S10P 18650 modules suggest that the parallel configuration would have a much more aggressive propagating failure. However, the propagation times through both batteries are comparable (approximately 50-60 seconds).

The primary difference observed between the 18650 and stacked pouch modules is that in this case the cells have a large area in direct contact with neighboring cells. Here, the thermal conductivity between neighboring cells is so strong that it overwhelms any impact the differing electrical connection may have. This indicates that poor insulation between cells would negate any safety features a battery may have to eliminate failure propagation, particularly for small, tightly packed modules.

\section{Conclusions}

This work examines the failure propagation behavior on differing cell types and electrical configuration. Cylindrical cells, even in a close pack configuration, have limited thermal contact between neighboring cells with significant air gaps present that limits the heat transfer between cells during 
thermal runaway. In this case, the impact of the electrical connections becomes more pronounced. Here, a parallel configuration leads to stronger propagation through the cylindrical cell module due both to heat transfer along the electrical connections as well as electrical shorting of the module through the initiated cell. It is important to note that in conventional battery system design, one strategy to mitigate the issue of cell shorting is through the use of blocking and discharge diodes to prevent unwanted current flow. However, the increased heat transfer the through the parallel configuration would not be mitigated through the use of blocking diodes.

The testing of stacked pouch cells demonstrates the impact when the heat transfer between neighboring cells is strong. This shows that with strong heat transfer between modules the impact of cell heating dwarfs any impact the electrical configuration may have, as thermal runaway propagates through the module at the same pace regardless of the electrical configuration. Initiation of runaway on the edge cell also gives a glimpse of how a propagating thermal runaway can compound the intensity of the runaway as it progresses through the module, as peak cell temperatures observed increase with each interior cell that goes into thermal runaway. The stacked pouch module data shows the limitations of mitigations built into the electrical system, as safeguards to block short circuit currents would have little impact in this case. This shows the need for engineering strategies to prevent the thermal interactions of cells during a runaway event, as well as electrical interactions, to prevent a catastrophic failure of a battery.

Future work in this area will continue to evaluate failure propagation using other experimental initiation triggers, studying different cell types, sizes, and chemistries, evaluating more sophisticated battery designs (with passive and active controls), and to simulate the propagation events for selected battery types and configurations through models. 


\section{Acknowledgements}

Funding for this work was provided by the U.S. Department of Energy Vehicle Technologies Program. We would like to thank our project sponsors David Howell and Brian Cunningham.

Sandia National Laboratories is a multi-program laboratory managed and operated by Sandia

Corporation, a wholly owned subsidiary of Lockheed Martin Corporation, for the U.S. Department of Energy's National Nuclear Security Administration under contract DE-AC04-94AL85000.

\section{List of figures}

Figure 1. Diagram showing arrangement of 18650 modules and thermocouple placement.

Figure 2. Diagram showing stacked pouch cell parallel module with bridge and thermocouple placement.

Figure 3. Cell skin temperature as a function of time during the 10S1P propagation test.

Figure 4. Cell and battery voltage as a function of time during the 10S1P propagation test.

Figure 1. Photograph of the 10S1P battery post-propagation test showing the penetration of Cell 6.

Figure 2. Cell skin temperature as a function of time during the 1S10P propagation test.

Figure 7. Battery voltage as a function of time during the 1S10P propagation test.

Figure 8. Photograph of the 1S10P battery post-propagation test.

Figure 9. Cell skin temperature and battery voltage as a function of time during the 5S1P propagation test initiated at the center cell (Cell 3).

Figure 10. Battery voltage and cell voltages during the 5S1P propagation test initiated at the center cell (Cell 3).

Figure 11. Photograph of the 5S1P battery post-propagation test initiated at the center cell (Cell 3).

Figure 12. Cell skin temperature and battery voltage as a function of time for the 5S1P propagation test initiated at Cell 1.

Figure 13. Battery and cell voltages for the 5S1P propagation test initiated at Cell 1.

Figure 14. Photograph of the 5S1P battery post-propagation test initiated at Cell 1.

Figure 15. Temperature profile of cell average temperatures at 10 second intervals for the 100 seconds following the initial induced runaway of Cell 1. 
Figure 16. Cell skin temperatures and battery voltage for the 1S5P propagation test initiated at Cell 3.

\section{References}

1. Musk, E., Model S Fire, in Tesla Blog2013.

2. Voelcker, J. Chrysler Yanks Plug-In Hybrid Test Fleet Off Roads, Will Replace Batteries. Green Car Reports 2012 [cited 2014 8-7-2014]; Available from:

http://www.greencarreports.com/news/1079368 chrysler-yanks-plug-in-hybrid-test-fleet-offroads-will-replace-batteries.

3. Lowy, J. Overcharging batteries eyed in Boeing 787 mishaps. Phys.org 2013 [cited 2014 8-72014].

4. Arbizzani, C., G. Gabrielli, and M. Mastragostino, Thermal stability and flammability of electrolytes for lithium-ion batteries. Journal of Power Sources, 2011. 196(10): p. 4801-4805.

5. Bandhauer, T.M., S. Garimella, and T.F. Fuller, A Critical Review of Thermal Issues in Lithium-Ion Batteries. Journal of The Electrochemical Society, 2011. 158(3): p. R1-R25.

6. Campion, C.L., W.T. Li, and B.L. Lucht, Thermal decomposition of LiPF6-based electrolytes for lithium-ion batteries. Journal of The Electrochemical Society, 2005. 152(12): p. A2327-A2334.

7. Dahn, J.R. and G.M. Ehrlich, Lithium-Ion Batteries, in Linden's Handbook of Batteries, T.B. Reddy, Editor. 2011, McGraw Hill: New York. p. 26.1-79.

8. Doughty, D.H., et al., Lithium battery thermal models. Journal of Power Sources, 2002. 110(2): p. 357-363.

9. Doughty, D.H., et al., Effects of additives on thermal stability of Li ion cells. Journal of Power Sources, 2005. 146(1-2): p. 116-120.

10. Fei, R., T. Cox, and W. Hsin, Thermal runaway risk evaluation of Li-ion cells using a pinch-torsion test. Journal of Power Sources, 2014. 249: p. 156-162.

11. Jeevarajan, J.A., et al., Performance characterization and safety testing of lithium-ion cells and battery for space flight applications. Lithium Batteries, Proceedings, ed. S. Surampudi, et al. Vol. 99. 2000, Pennington: Electrochemical Society Inc. 694-705.

12. Jhu, C.Y., et al., Self-reactive rating of thermal runaway hazards on 18650 lithium-ion batteries. Journal of Thermal Analysis and Calorimetry, 2011. 106(1): p. 159-163.

13. Kim, G.-H., A. Pesaran, and R. Spotnitz, A three-dimensional thermal abuse model for lithium-ion cells. Journal of Power Sources, 2007. 170(2): p. 476-489.

14. Roth, E.P., Abuse response of 18650 Li-Ion cells with different cathodes using EC:EMC/LiPF6 and EC:PC:DMC/LiPF6 electrolytes. Battery Safety and Abuse Tolerance at the 212th ECS Meeting, 2008: p. 19-4141.

15. Roth, E.P., et al., Advanced technology development program for lithium-ion batteries: thermal abuse performance of 18650 Li-ion cells. SAND2004-0584, 2004, Sandia National Laboratories: Albuquerque, NM.

16. Spotnitz, R.M., et al., Simulation of abuse tolerance of lithium-ion battery packs. Journal of Power Sources, 2007. 163(2): p. 1080-1086.

17. Offer, G.J., et al., Module design and fault diagnosis in electric vehicle batteries. Journal of Power Sources, 2012. 206(0): p. 383-392. 
18. Friel, D.D., Battery Design, in Linden's Handbook of Batteries, T.B. Reddy, Editor. 2011, McGraw Hill: New York. p. 5.1-5.23.

19. Sun, H., et al., Three-dimensional thermal modeling of a lithium-ion battery pack. Journal of Power Sources, 2012. 206(0): p. 349-356.

20. Kim, G.-H., et al., Fail-safe design for large capacity lithium-ion battery systems. Journal of Power Sources, 2012. 210(0): p. 243-253.

21. Lu, L., et al., A review on the key issues for lithium-ion battery management in electric vehicles. Journal of Power Sources, 2013. 226(0): p. 272-288.

22. Troxler, Y., et al., The effect of thermal gradients on the performance of lithium-ion batteries. Journal of Power Sources, 2014. 247(0): p. 1018-1025.

23. Wu, B., et al., Coupled thermal-electrochemical modelling of uneven heat generation in lithiumion battery packs. Journal of Power Sources, 2013. 243(0): p. 544-554.

24. Wu, M.S., et al., Correlation between electrochemical characteristics and thermal stability of advanced lithium-ion batteries in abuse tests - short-circuit tests. Electrochimica Acta, 2004. 49(11): p. 1803-1812.

25. Lamb, J. and C.J. Orendorff, Evaluation of mechanical abuse techniques in lithium ion batteries. Journal of Power Sources, 2014. 247: p. 189-196. 
Table 1. Cell and battery specifications for test articles used for propagation testing

\begin{tabular}{|c|l|l|l|}
\hline \multicolumn{1}{|c|}{ Battery } & \multicolumn{1}{c|}{ Chemistry } & \multicolumn{1}{c|}{ Geometry } & \multicolumn{1}{c|}{ Configuration } \\
\hline $2200 \mathrm{mAh} 18650$ & $\mathrm{LiCoO}_{2} /$ Graphite & cylindrical & $10 \mathrm{~S} 1 \mathrm{P}, 1 \mathrm{~S} 10 \mathrm{P}$ \\
\hline $3000 \mathrm{mAh}$ pouch & $\mathrm{LiCoO}_{2} /$ Graphite & pouch & 5S1P, 1S5P \\
\hline
\end{tabular}




\section{Figures}
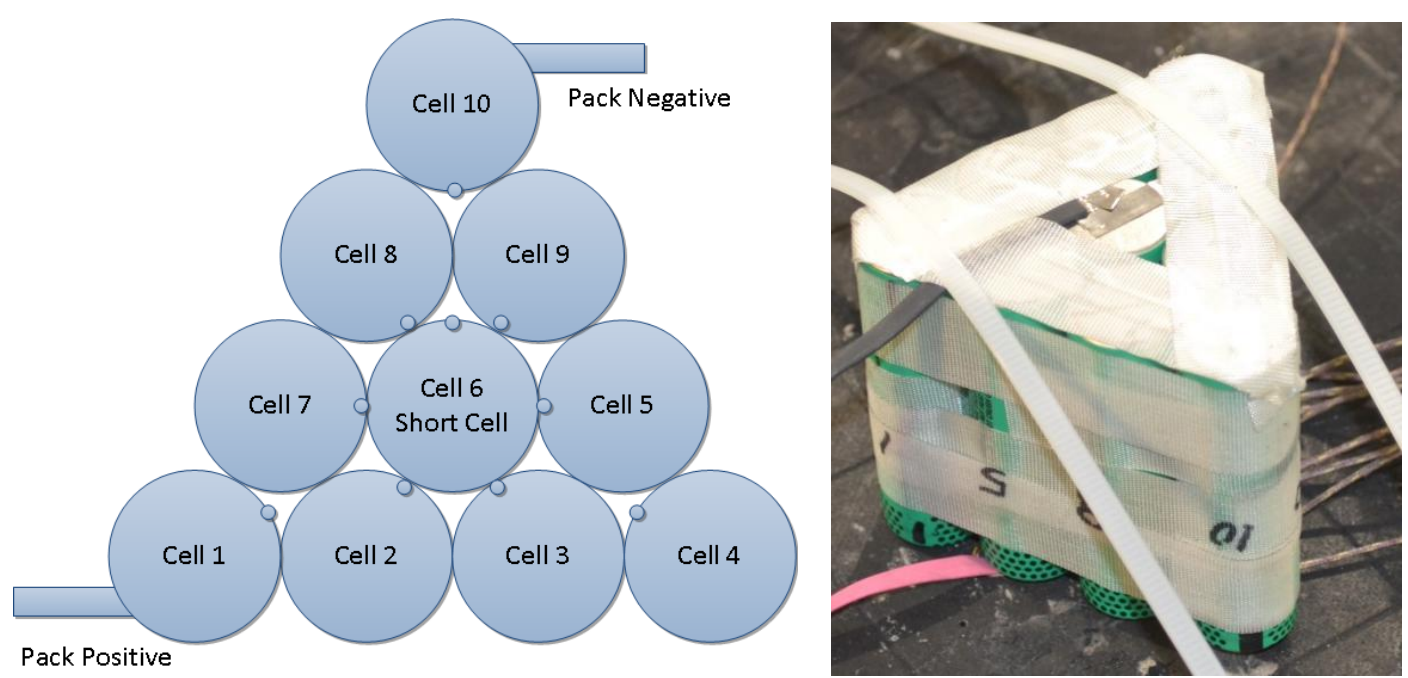

Figure 1. Diagram showing arrangement of 18650 modules and thermocouple placement.

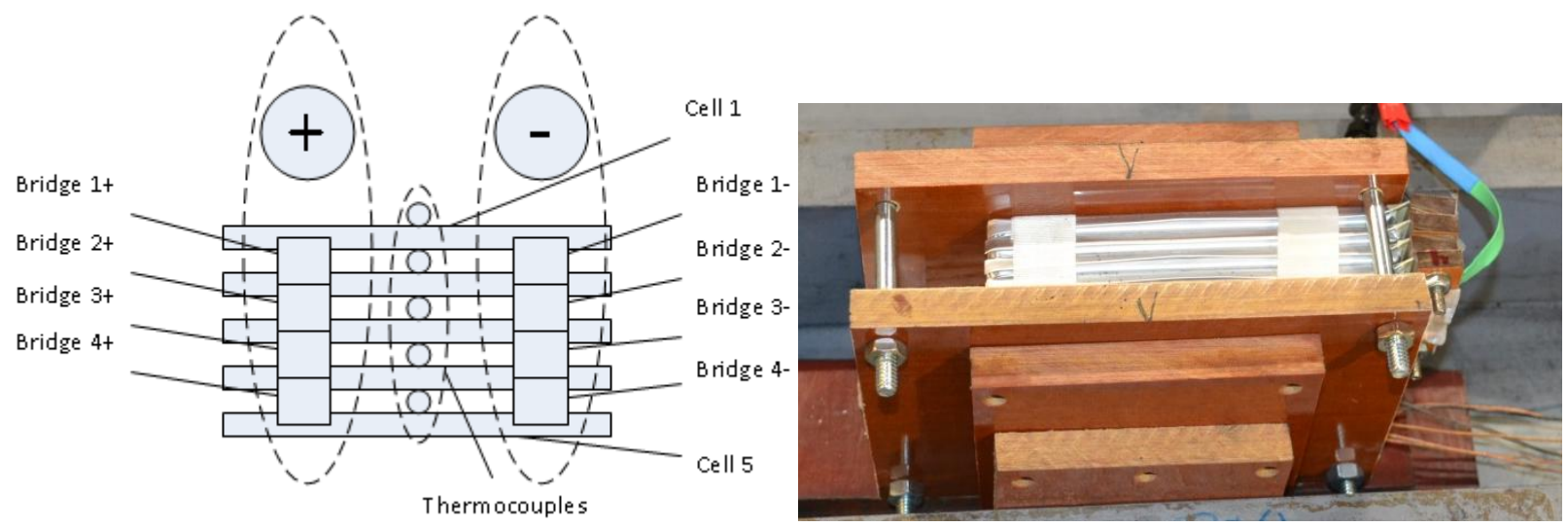

Figure 2. Diagram showing stacked pouch cell parallel module with bridge and thermocouple placement. 

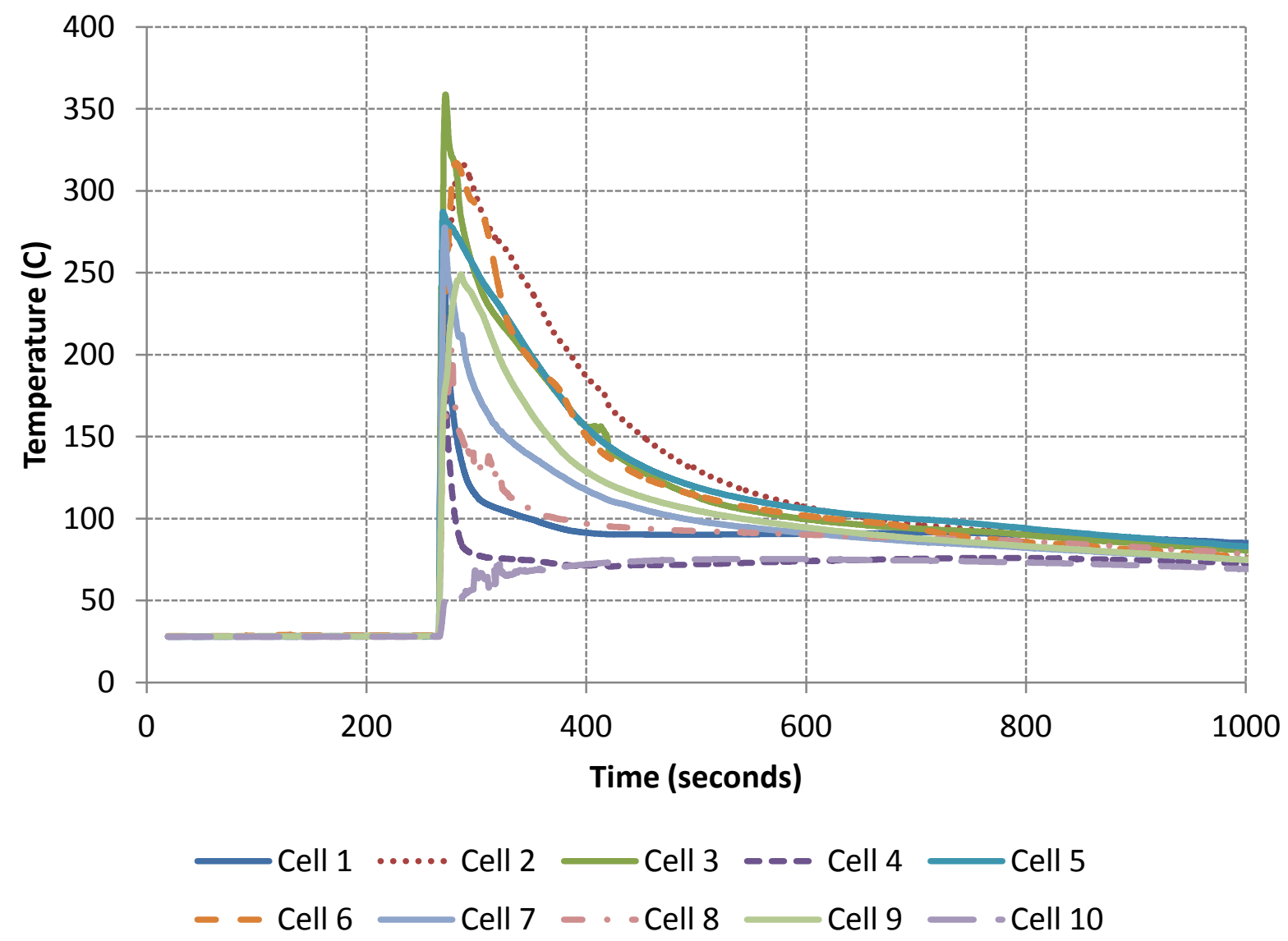

Figure 3. Cell skin temperature as a function of time during the 10S1P propagation test. 


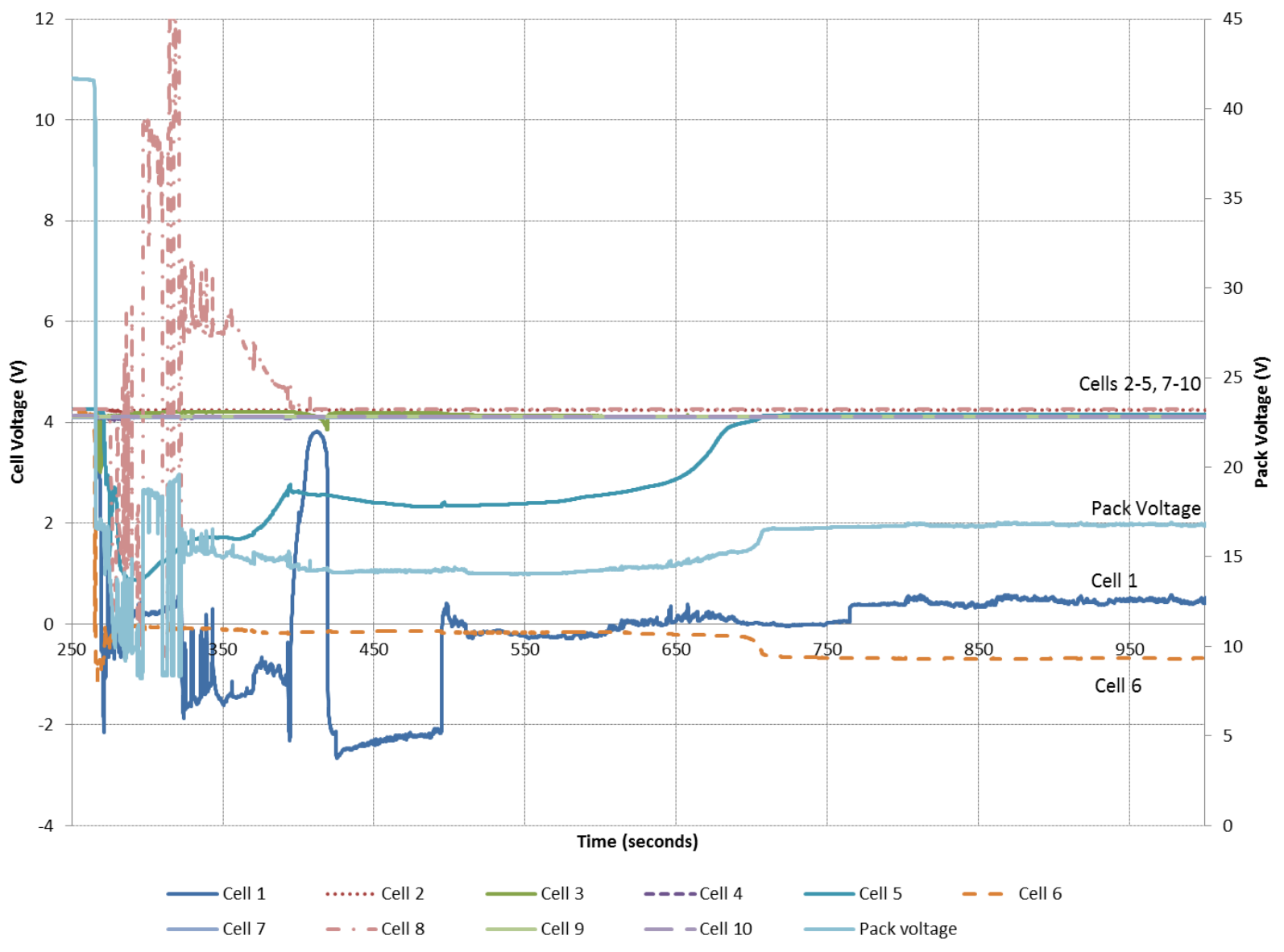

Figure 4. Cell and battery voltage as a function of time during the 10S1P propagation test.

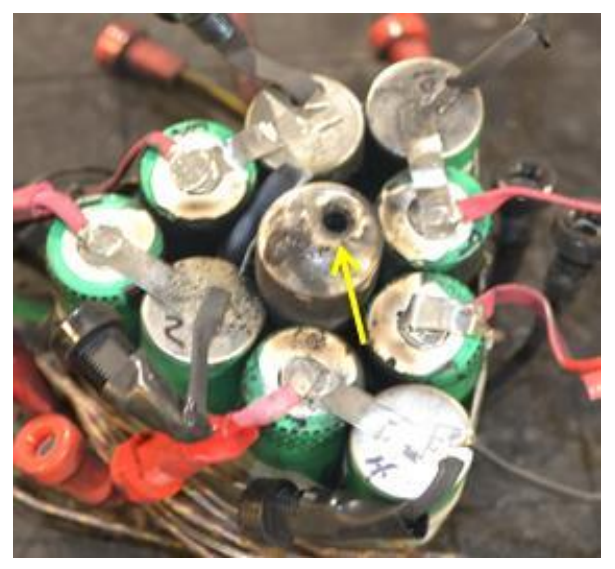

Figure 1. Photograph of the 10S1P battery post-propagation test showing the penetration of Cell 6. 


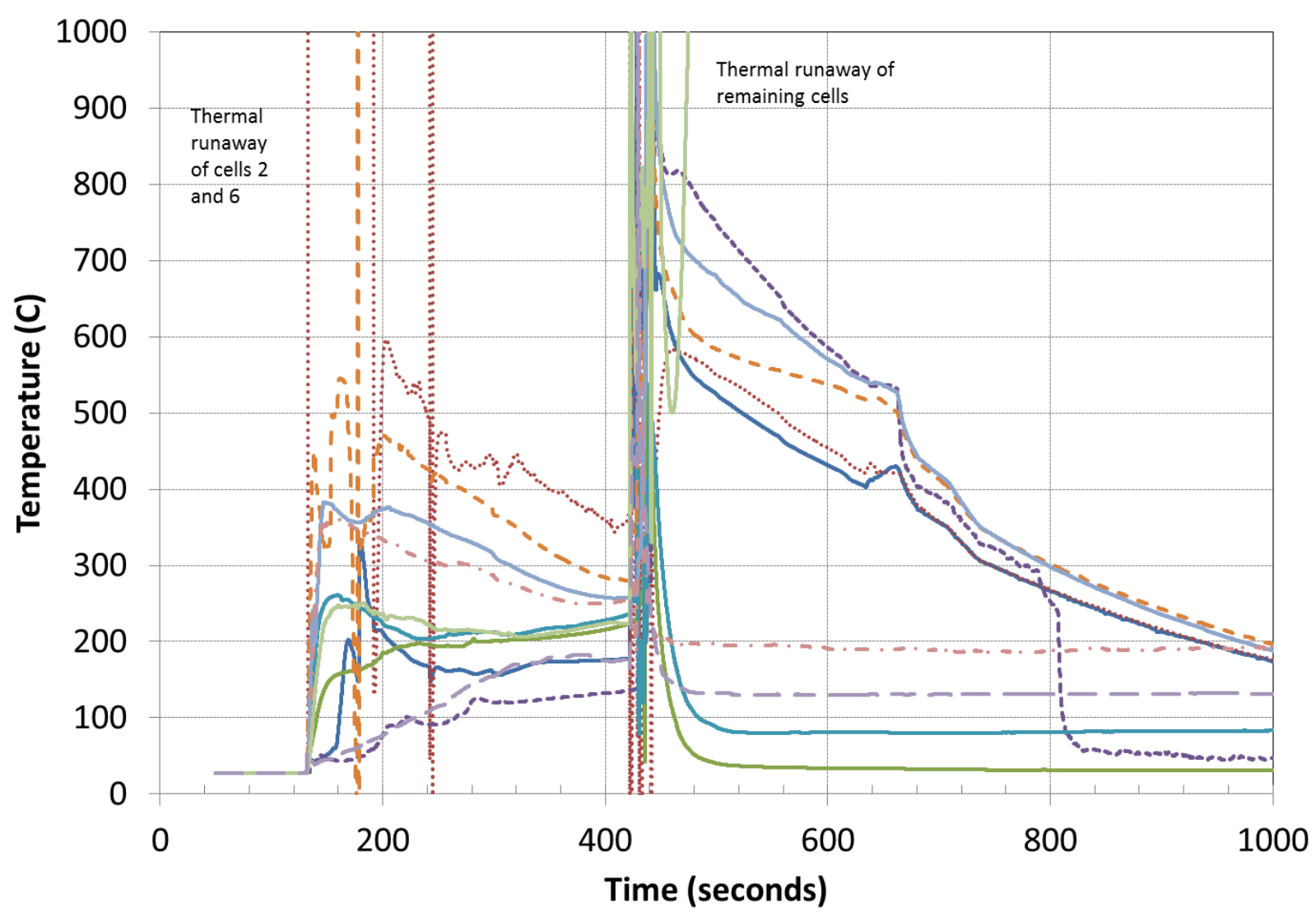

- Cell $1 \cdots \cdots \cdot$ Cell $2-$ Cell $3-\cdots-$ Cell $4-$ Cell $5--$ Cell $6-$ Cell $7-\cdots-$ Cell $8-$ Cell $9--$ Cell 10

Figure 2. Cell skin temperature as a function of time during the 1S10P propagation test. 


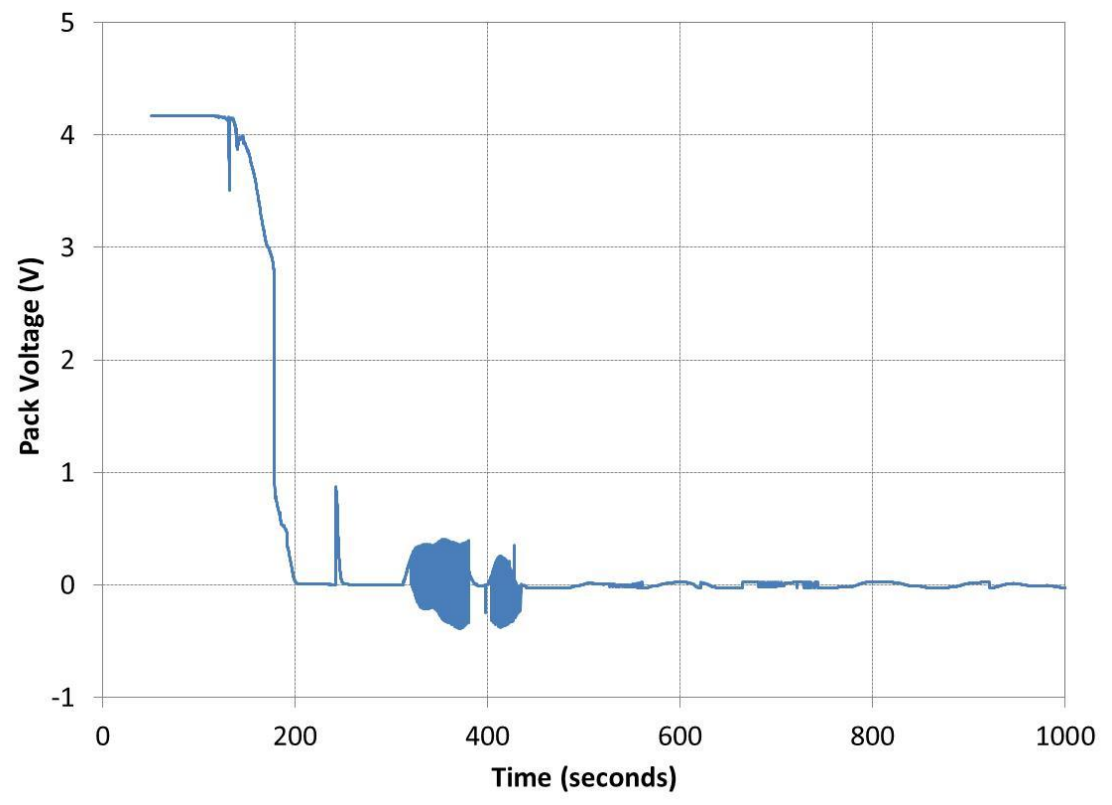

Figure 7. Battery voltage as a function of time during the 1S10P propagation test.

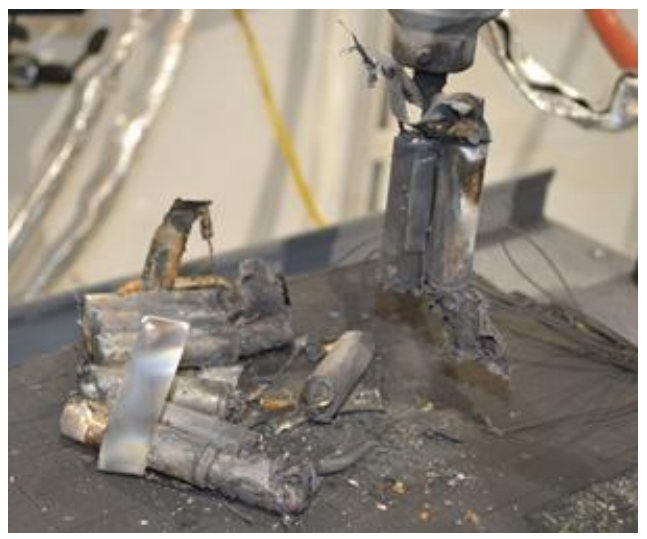

Figure 8. Photograph of the 1S10P battery post-propagation test. 


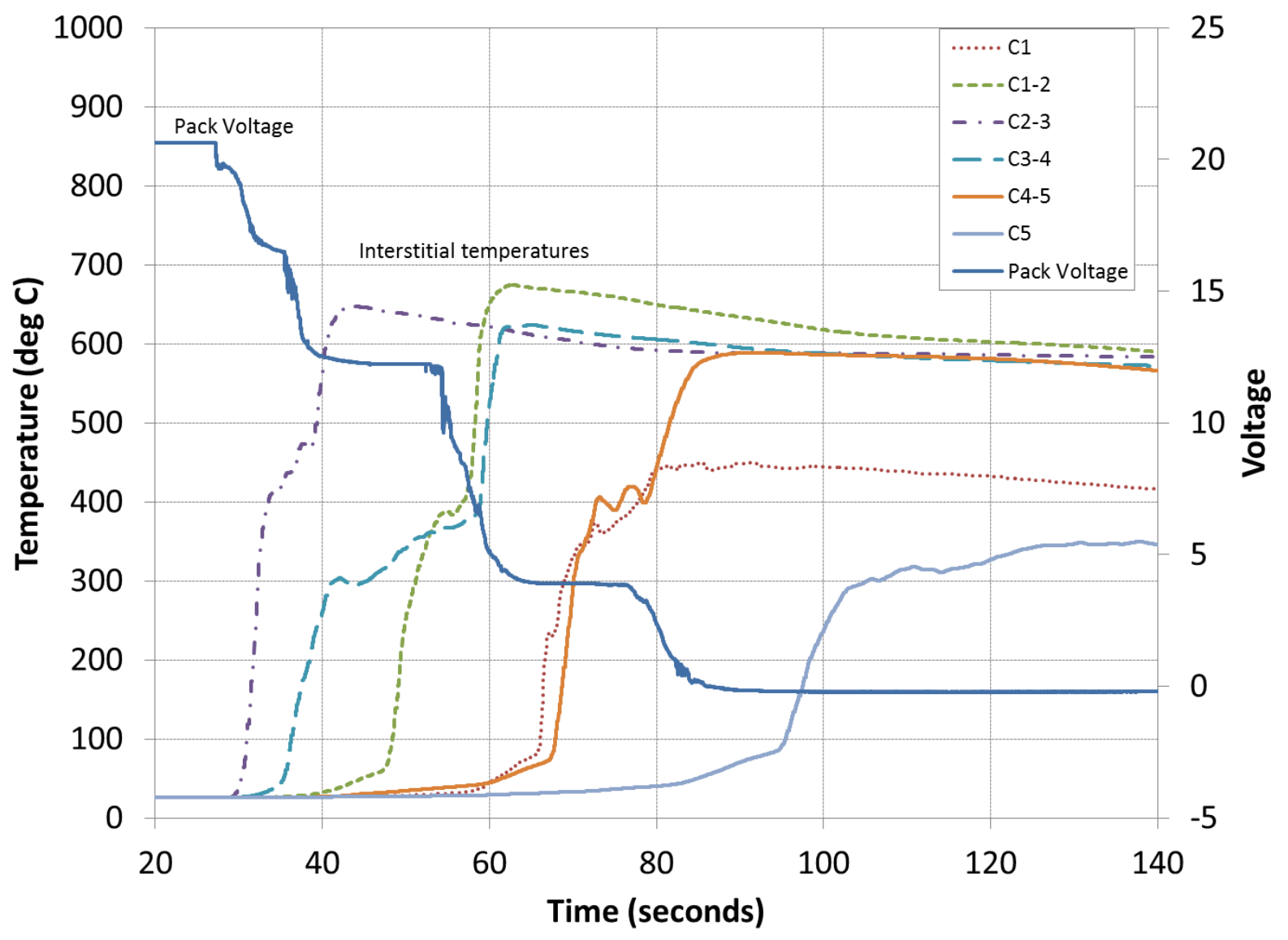

Figure 9. Cell skin temperature and battery voltage as a function of time during the 5S1P propagation test initiated at the center cell (Cell 3). 


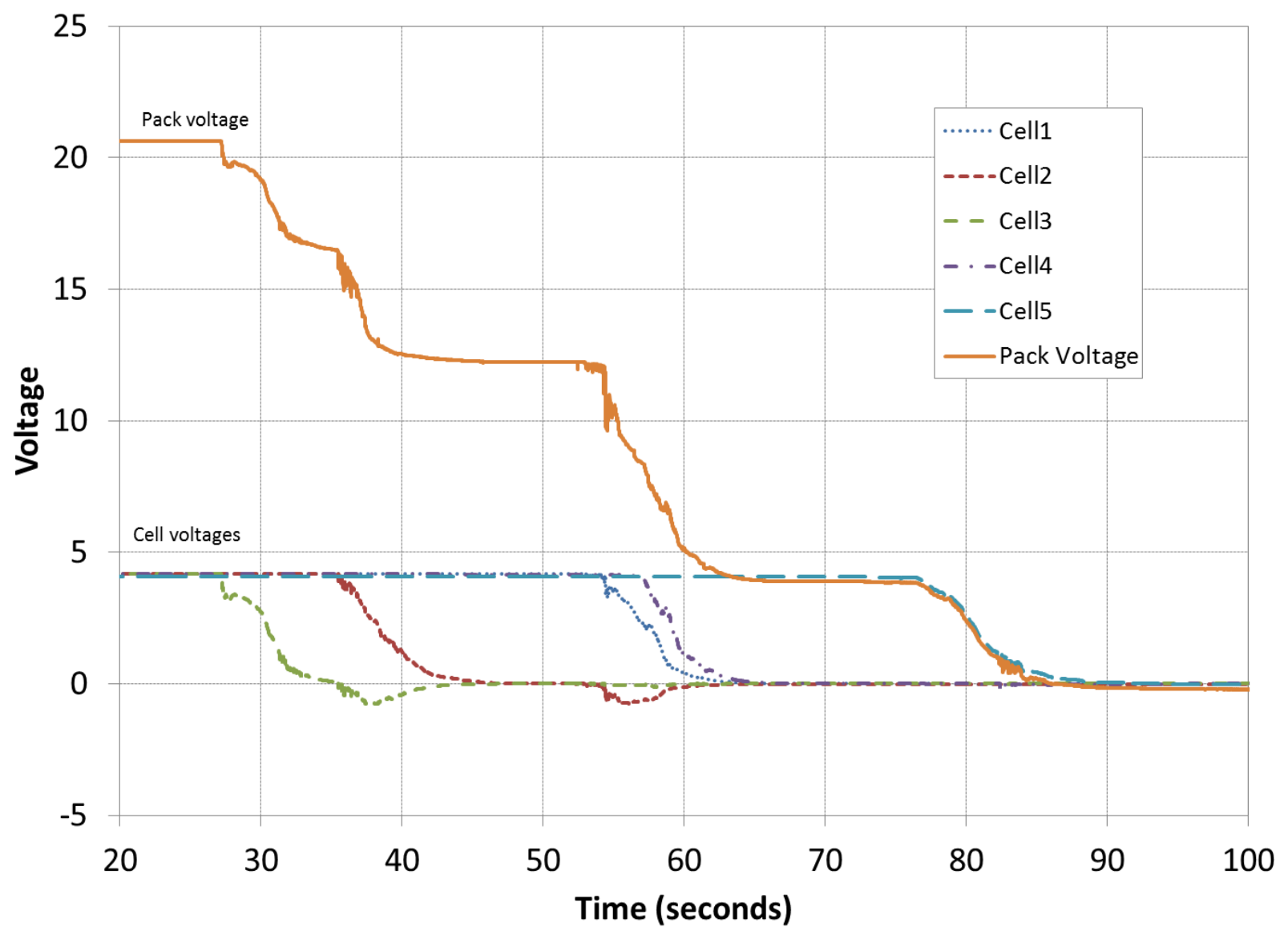

Figure 10. Battery voltage and cell voltages during the 5S1P propagation test initiated at the center cell (Cell 3). 


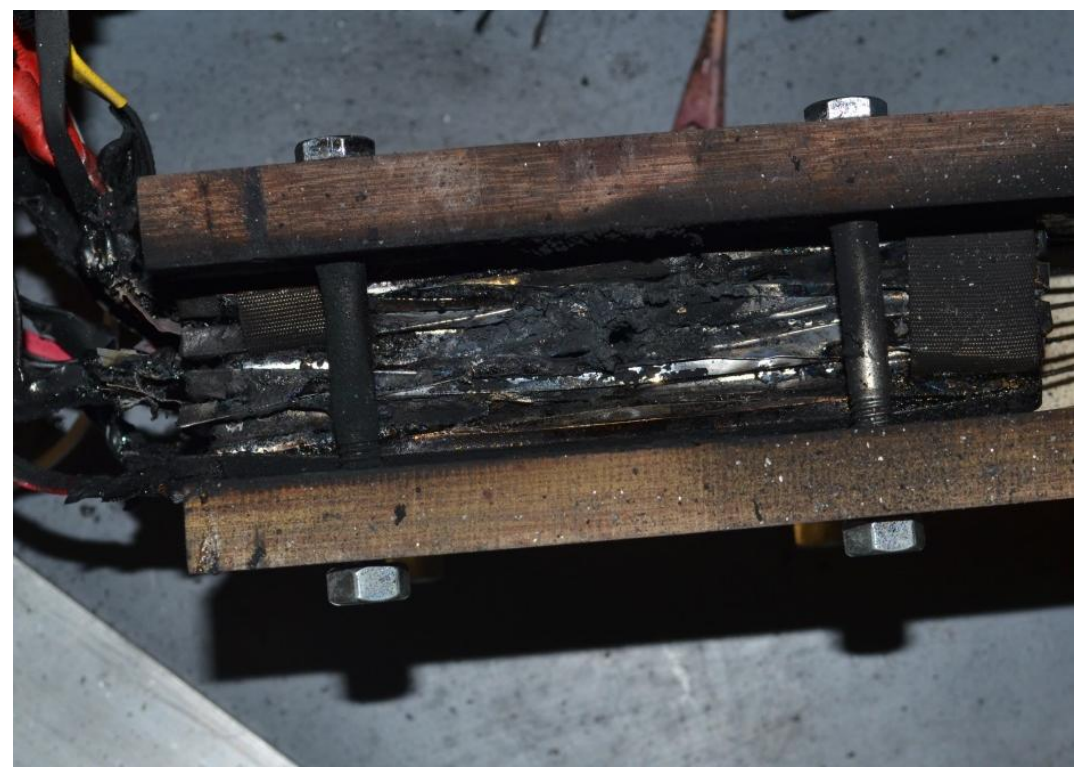

Figure 11. Photograph of the 5S1P battery post-propagation test initiated at the center cell (Cell 3).

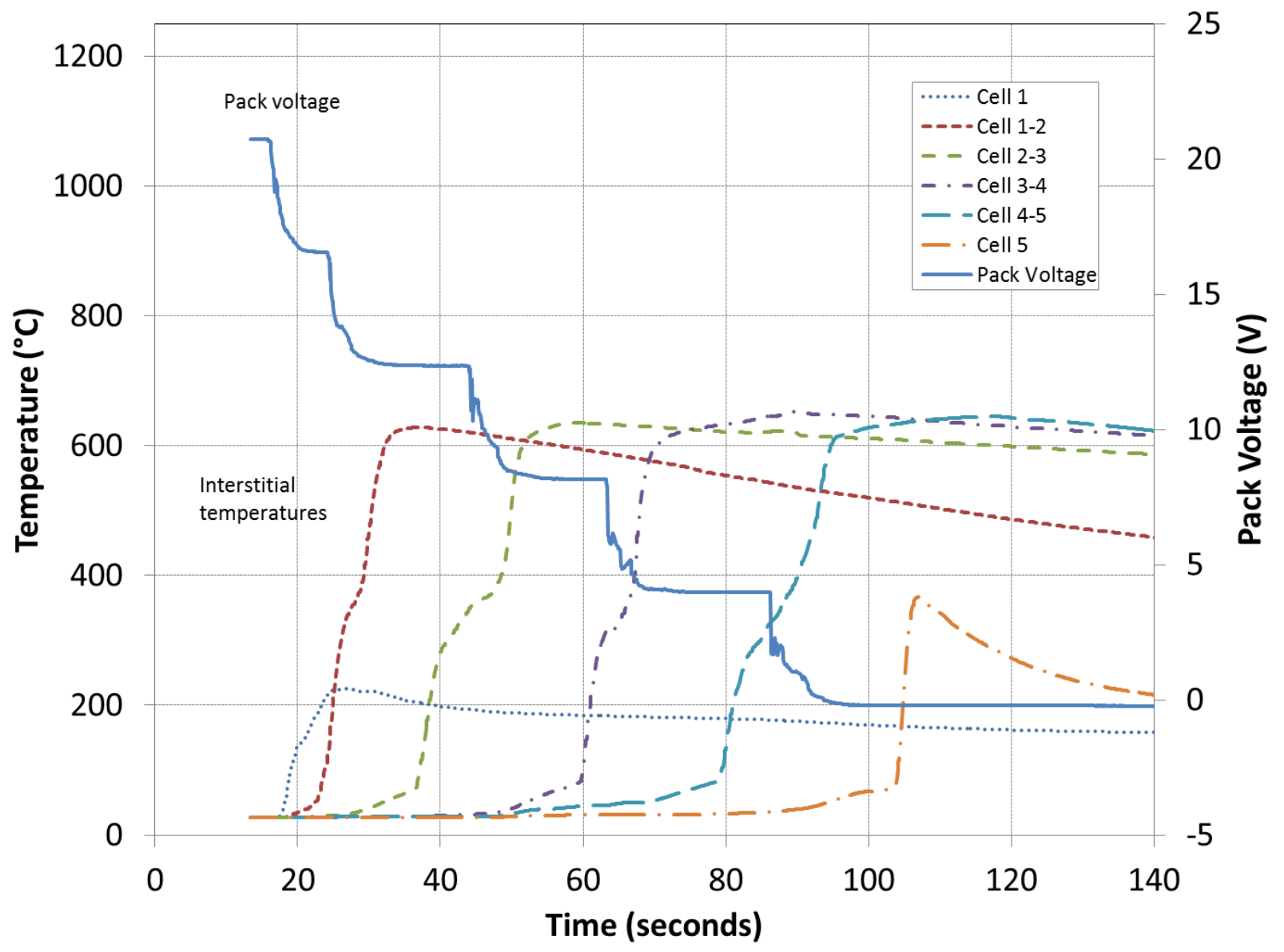

Figure 12. Cell skin temperature and battery voltage as a function of time for the 5S1P propagation test 
initiated at Cell 1.

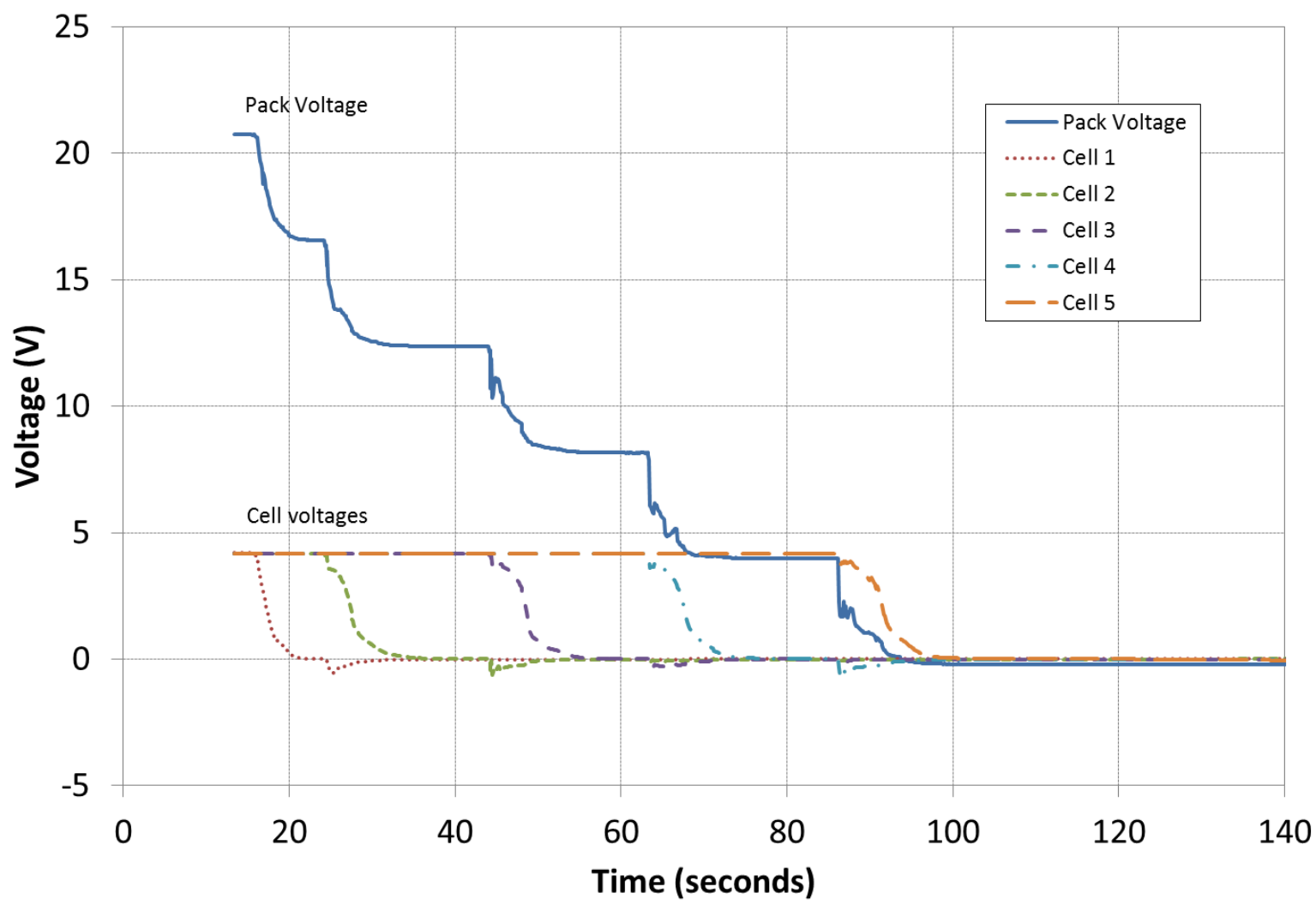

Figure 13. Battery and cell voltages for the 5S1P propagation test initiated at Cell 1.

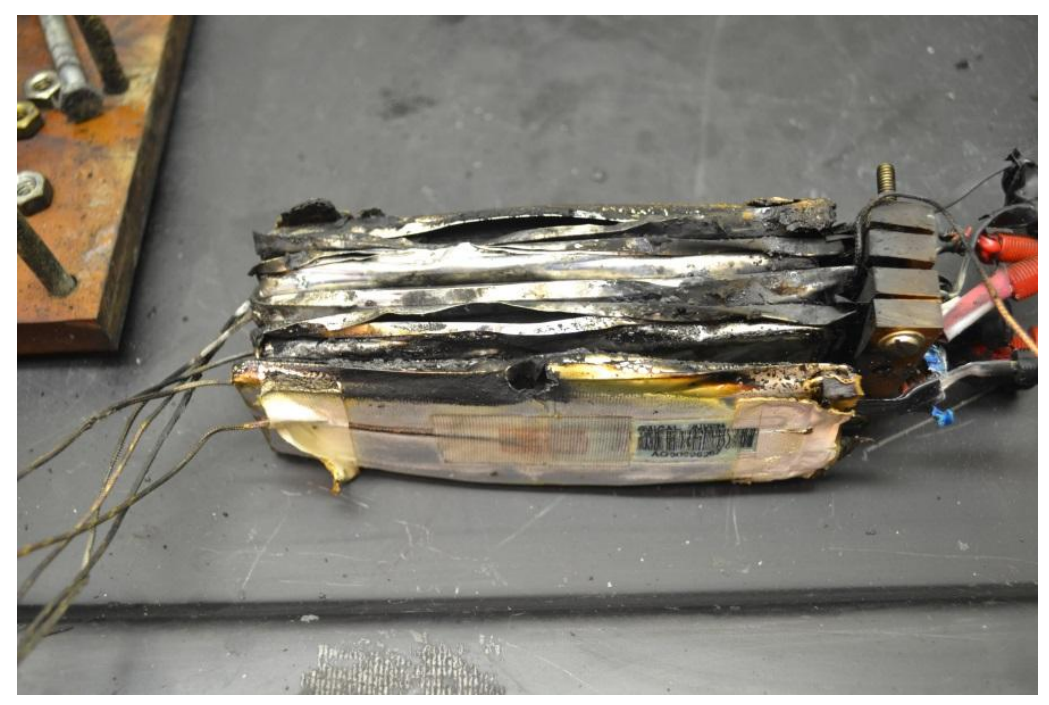

Figure 14. Photograph of the 5S1P battery post-propagation test initiated at Cell 1. 


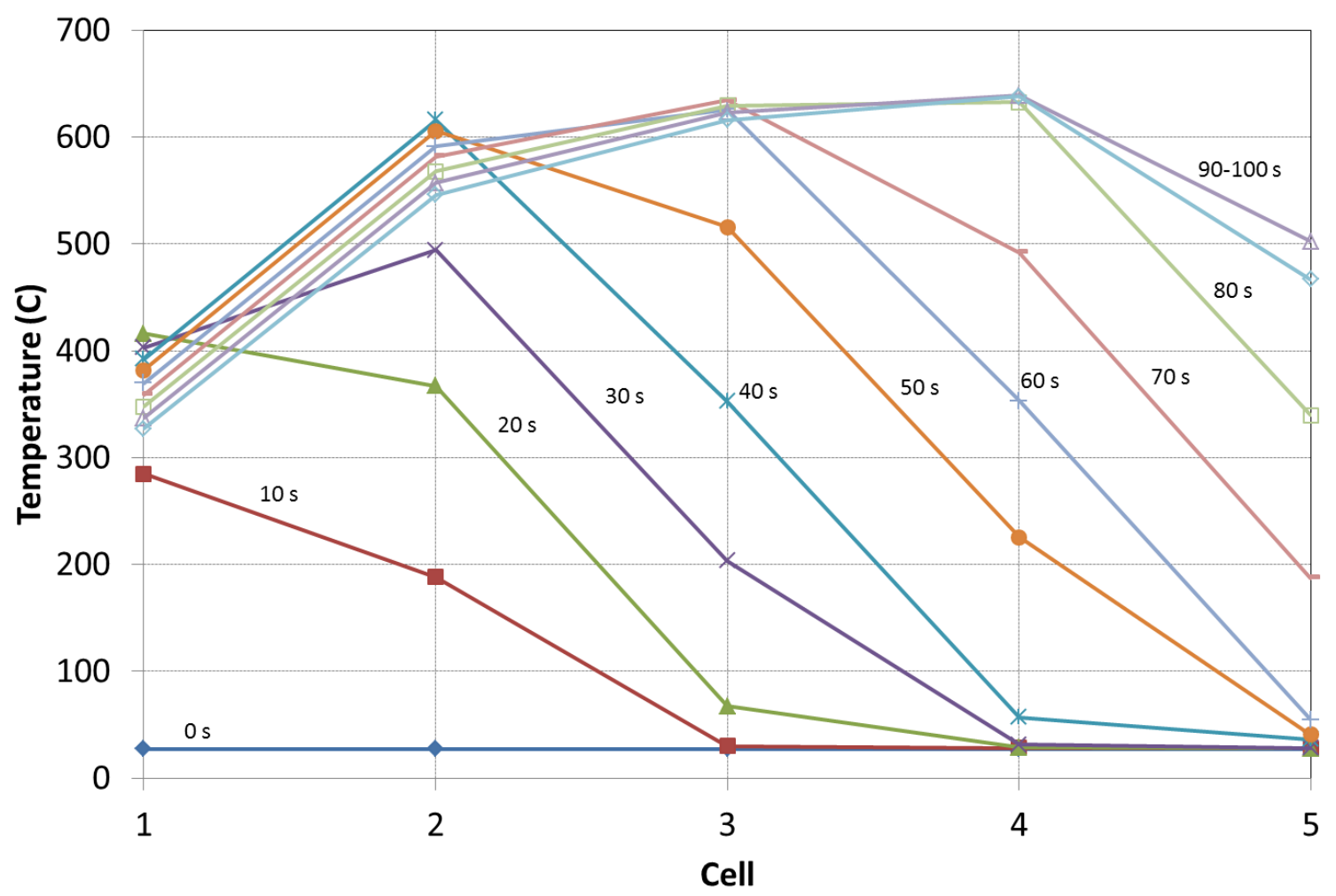

$\rightarrow 0 \mathrm{~s} \rightarrow-10 \mathrm{~s} \rightarrow-20 \mathrm{~s}-30 \mathrm{~s} * 40 \mathrm{~s} \rightarrow-50 \mathrm{~s}+60 \mathrm{~s}-70 \mathrm{~s}-80 \mathrm{~s}\lrcorner 90 \mathrm{~s}-100 \mathrm{~s}$

Figure 15. Temperature profile of cell average temperatures at 10 second intervals for the 100 seconds following the initial induced runaway of Cell 1. 


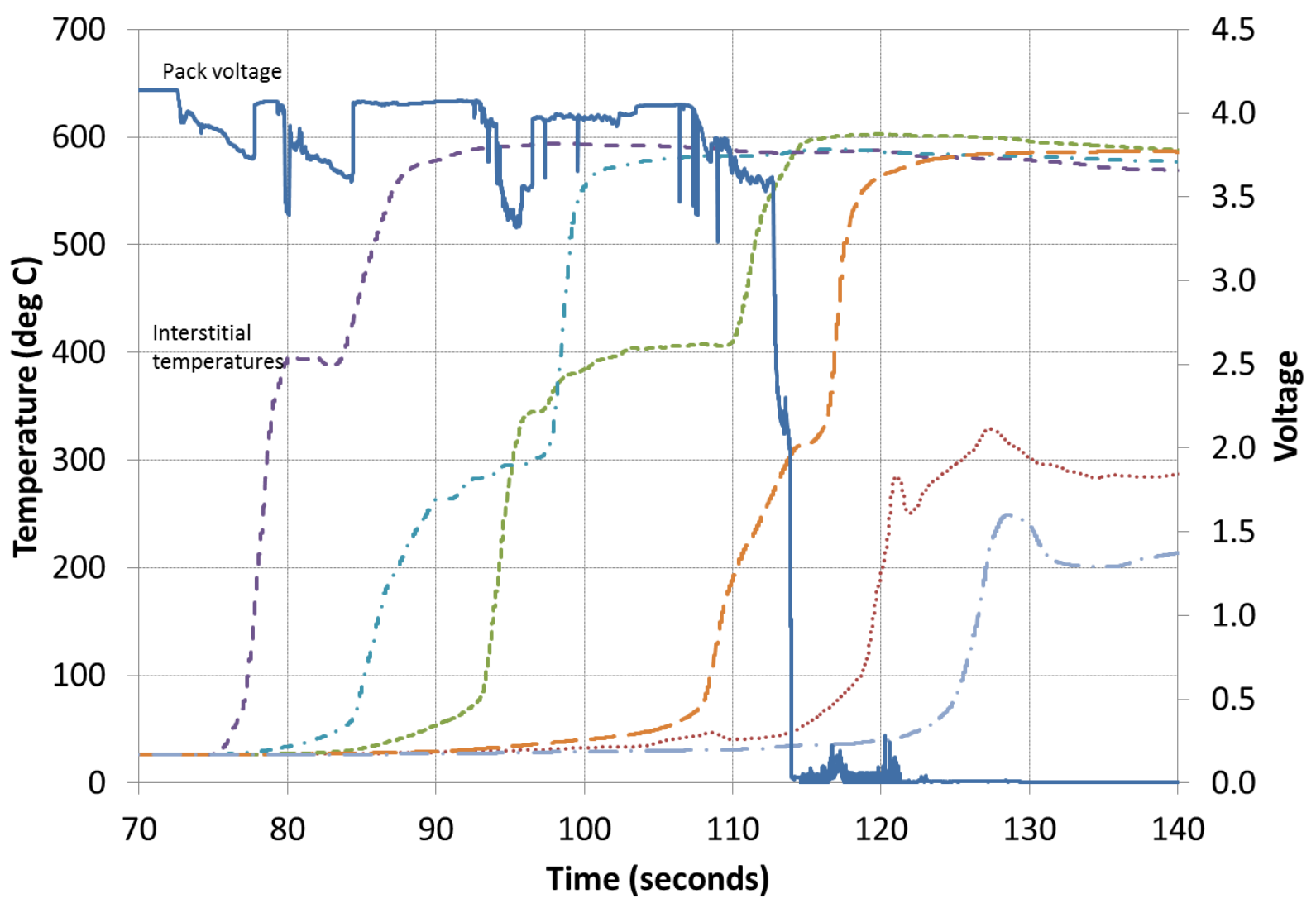

C1 ---.C1-2 - - C2-3 -.-C3-4 - -C4-5 - C5 - Cell Voltage

Figure 16. Cell skin temperatures and battery voltage for the 1S5P propagation test initiated at Cell 3. 